Recibido: 2020-05-04

Aceptado: 2021-01-07

\section{Cómo citar este artículo:}

Tomé, S. Los barrios y viviendas de los gitanos en la región noroeste de España. Revista INVI, 36(101), 227-255. https://doi.org/10.4067/S071883582021000100227

Este trabajo es una aportación al proyecto "Paisajes de la Desigualdad en la Periferia de las Ciudades", del Programa Estatal de Generación de Conocimiento y Fortalecimiento Científico y Tecnológico del Sistema de I+D+I, referencia PGC 2018-098209-B-100.

\section{Sergio Tomé}

Departamento de Geografía, Universidad de Oviedo, España, stome@uniovi.es,

https://orcid.org/0000-0001-8741-7017 


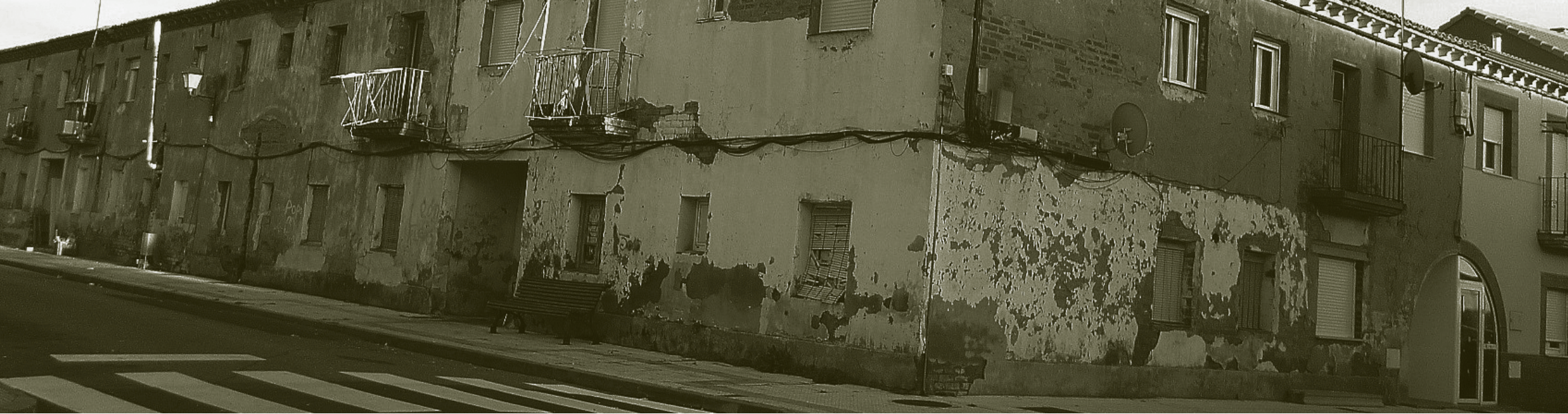

\title{
LOS BARRIOS Y VIVIENDAS DE LOS GITANOS EN LA REGIÓN NOROESTE DE ESPAÑA
}

\begin{abstract}
Resumen
En este artículo se analizan las soluciones utilizadas para intentar resolver el problema habitacional del pueblo gitano en la red urbana del territorio noroccidental español, desde mediados del siglo XX hasta la fecha. Su interés radica tanto en la trayectoria común como en la considerable diversidad de situaciones y respuestas. Se emplea una metodología geográfica basada en la aproximación diacrónica, la dialéctica entre lo cuantitativo y cualitativo, la comparativa y la consideración del hábitat como elemento expresivo de las relaciones espaciales en el paisaje. Entre sus principales resultados, el texto proporciona una lectura transversal del urbanismo y la edificación en las denominadas no go zones, incorporando los matices necesarios para evitar generalizaciones simplistas. Se explican los diferentes ritmos y experiencias dentro de una misma evolución hacia la vivienda normal, enfatizando el peso sustantivo de las variables territoriales, el contexto regional y los factores locales, más allá de las decisiones políticas.
\end{abstract}

Palabras clave: urbanismo, hábitat, romas, exclusión, alojamiento social. 


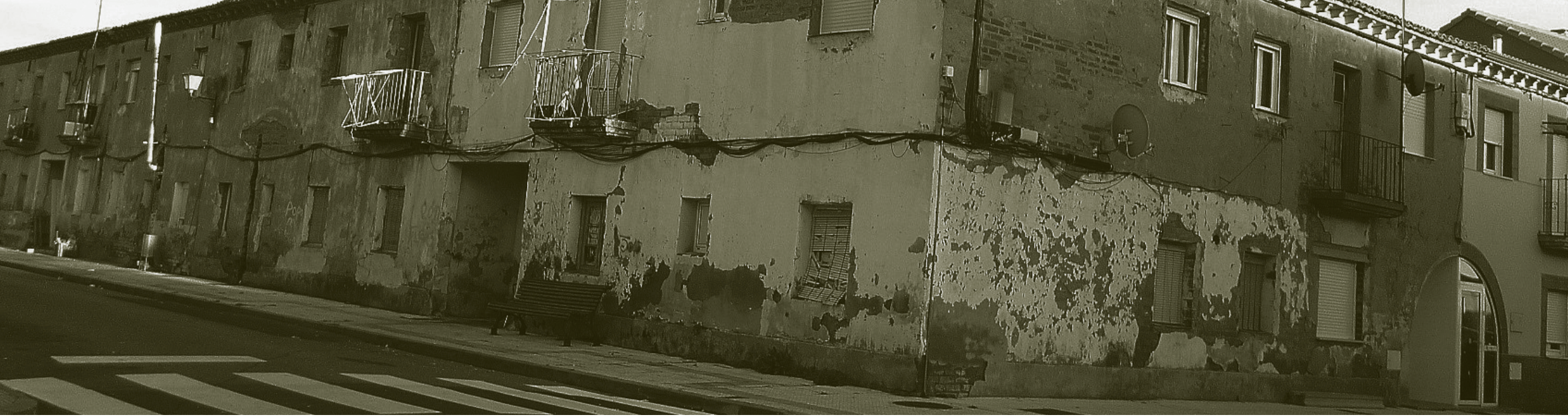

\section{Abstract}

The article analyzes the solutions used to resolve the housing problem of Roma people since the mid-twentieth century in cities of northwestern Spain. Its interest lies in a common trajectory and in various situations and responses, which have not been successful. We use a geographical methodology based on the diachronic approach, the dialectical method between the quantitative and qualitative, the comparative, and the consideration of habitat as an expressive element of spatial relations in the landscape. Among its main results, this paper interprets a cross-sectional reading of urbanism and architecture in the so-called nogo zones incorporating the necessary nuances to avoid simplistic generalizations. These explain different rhythms and experiences in the same development towards typical housing, emphasizing the substantive weight of territorial variables, the regional context, and local factors beyond political decisions.

\section{THE NEIGHBORHOODS AND DWELLINGS OF THE GYPSIES IN THE NORTHWESTERN REGION OF SPAIN}

Keywords: Town planning, habitat, gypsies, exclusion, social housing. 


\section{*.*vis revistainvi}

\section{Introducción y presentación del estudio}

El alojamiento deficiente ha sido un factor esencial en la marginación histórica de los gitanos españoles, en su mayoría sedentarios (Hernández et al., 2019) y cuyo número se estimaba cercano a los 600.000 en 2018. España ha seguido en líneas generales la misma política que los estados de su entorno en cuanto a normalización progresiva de la vivienda, pero su esfuerzo estatal en diagnóstico e inversiones ha posibilitado un nivel de integración comparativamente superior al de la Europa meridional y oriental (Artoni, 2015; Caselles, 2013; Fundación Secretariado Gitano, 2016). Las estadísticas para el conjunto nacional esconden sin embargo fuertes disparidades regionales, déficits persistentes y retrocesos causados por los recortes en política social, que conducen localmente a una perpetuación de los barrios-gueto. Esa falla despierta interés en medios periodísticos, universitarios y gubernamentales de ciertas regiones, pero falta el acercamiento integral a una problemática mucho más compleja que el propio hecho de la infravivienda. Aquí se aporta una mirada de conjunto a la evolución de los modelos habitacionales, las formas de asentamiento y al patrón de localización intraurbana en una fracción significativa del país. Se sistematizan y completan las aportaciones previas, profundizando en la explotación geográfica de los datos disponibles para cada ciudad, por barrios, a fin de contextualizarlos y darles sentido. De ahí la aproximación urbanística, con cierto detalle, a la forma física y las configuraciones espaciales mediante las cuales los gitanos se insertan en el escenario urbano y cambian con el tiempo su lugar de residencia.

Para relativizar los conocimientos referidos al marco estatal se adoptó un ámbito de estudio menor, el de la región noroccidental, integrada por diez provincias pertenecientes a cuatro Comunidades Autónomas. La atención se centró en las veinticuatro ciudades y municipios integrantes de aglomeraciones, con tamaño mediano; más de 17.000 habitantes y menos de 300.000 en términos municipales, aunque el área urbana funcional de la mayor de ellas, Vigo, alcanza el medio millón (figura 1). Entre todas suman poco más de cinco mil viviendas habitadas por gitanos. La elección no sólo obedece a la cercanía física del investigador, pues se trata de un territorio con distintos niveles de desarrollo, a favor de la costa y en detrimento del interior, donde los gobiernos locales o regionales han aplicado políticas de diferente signo, más conservadoras o progresistas según los casos. Hay desequilibrios internos en cuanto a la inversión realizada, y varía la naturaleza de las acciones puestas en práctica en cada lugar: unas han sido convencionales y otras novedosas, con la ventaja de aplicarlas a cantidades de población manejables. Eso no impide que una parte de la zona estudiada figure a la cabeza del país por cifra de infraviviendas, así que la casuística local resulta de gran interés. 


\section{粼 revistainvi}

Figura 1.

Área de estudio y viviendas habitadas por gitanos en las ciudades.

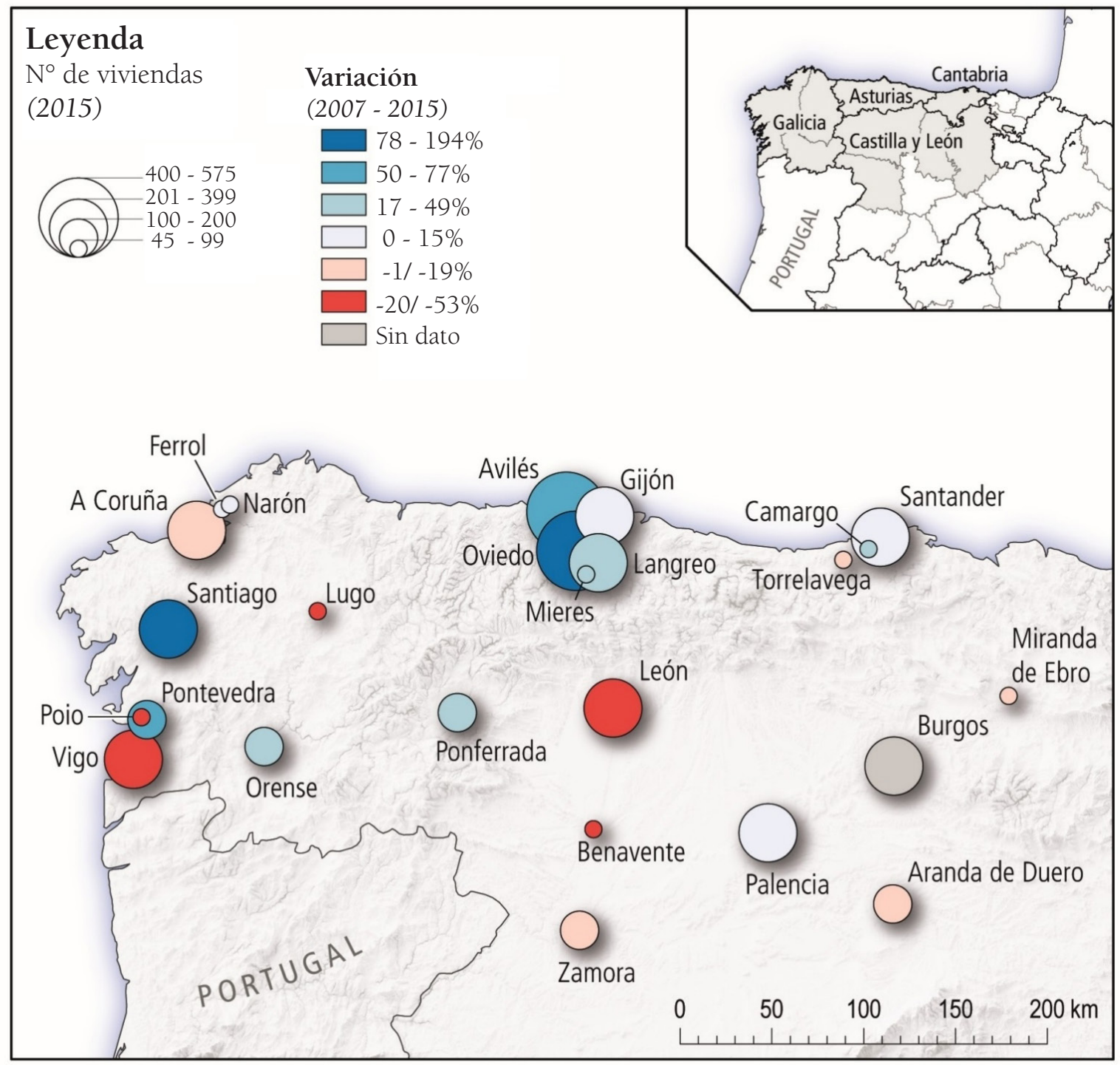

Fuente: Google Maps, y Fundación Secretariado Gitano. Elaboración propia. 


\title{
*.*vis revistainvi
}

\section{Descripción de la problemática y estado del arte}

\begin{abstract}
Puede efectuarse un mínimo acercamiento transdisciplinar al estado de la cuestión a partir de las publicaciones (básicamente europeas) de los últimos veinte años, tanto de tipo académico -procedentes de campos afines a la Geografía- como de carácter divulgativo. Clasificándolas por su contenido y escala de análisis, de menor a mayor, resulta destacable en el nivel de aproximación subcontinental el estudio de Macura (1999) acerca de la Europa Centro Oriental; este fija con carácter general las tipologías del hábitat gitano asociándolas con su entorno. A escala de país existen comparaciones Francia-Italia (Legros y Vitale, 2011) y monografías sobre Grecia o Portugal, que tratan el problema residencial como factor de exclusión (Ziomas et al., 2011) y las políticas de reubicación e integración (Castro, 2007; Castro y Correia, 2008). Ponen en evidencia ciclos de evolución semejantes, con desfases cronológicos entre países, desde el alojamiento precario al de tipo social; en estos, en principio, las soluciones son temporales y después definitivas, sin cubrir todas las necesidades. Las investigaciones locales resultan ser las más numerosas, sobre todo las francesas e italianas. Normalmente están dedicadas a grupos diferenciados (rumanos, nómadas u otros) (Delépine, 2007), y estudian tanto las formas de asentamiento, alojamiento y segregación (Cingolani, 2016) como la gobernanza (Potot, 2016), los traslados y desplazamientos debidos a la gentrificación (Amador, 2018; Yeamreg, 2018). En el caso de los gitanos viajeros, la atención se centra en el patrón de movilidad y las políticas de estacionamiento (Bergeon, 2014). El peso de ese grupo en el Reino Unido explica que allí la información disponible se refiera sobre todo a los problemas planteados por el paso a viviendas fijas no integradas (Greenfields y Smith, 2010) y la restricción creciente de los espacios donde está permitido acampar (Nugent, 2018). Las aportaciones británicas hacen particular hincapié en las desigualdades de salud (Condon et al., 2019; Van Cleemput, 2008). Precisamente la falta de registros estadísticos exhaustivos sobre el tamaño del colectivo y su localización llevó a poner en marcha en Londres un mapa interactivo ("Mapping For Change", 2017).
\end{abstract}

En España las principales contribuciones vienen de la Fundación Secretariado Gitano, especialmente el Estudio-Mapa sobre Vivienda y Población, en sus dos ediciones (2007 y 2016). Desagrega los datos por núcleos de población y barrios, también por nacionalidades en algunas comunidades, y detalla por provincias la naturaleza de los lugares de residencia y las modalidades de habitación dominantes. Ya con anterioridad, el Ministerio de Fomento había publicado el Análisis Urbanístico de Barrios Vulnerables (Hernández Aja, 1997), de indudable valor para el objeto de estudio. Es forzoso citar asimismo los trabajos de Vallvé (2009), Caselles (2013) y Poza (2014), que ofrecen diagnósticos sobre la problemática de vivienda del colectivo y el efecto de las acciones estatal y autonómica. En el Noroeste español Asturias posee investigaciones específicas acerca del chabolismo y su redención, referidas a Avilés y Gijón (Agulló et al., 2004; Martínez y Vázquez, 2000). En Galicia, deben nombrarse al menos el plan municipal de erradicación de asentamientos precarios de La Coruña (Ayuntamiento de A Coruña, 2016), y el estudio provincial de idéntica índole auspiciado por la 


\section{*.*vis revistainvi}

Diputación (Botana, 2019). La autora de este último, Cristina Botana, tiene otra publicación dedicada a barrios segregados en Galicia y presentó en septiembre de 2020 su Trabajo Fin de Máster sobre la infravivienda en La Coruña, sin publicar a fecha de hoy, mientras realiza la Tesis Doctoral acerca del mismo asunto (Botana, 2020; Malvido, 2020). En cuanto a Latinoamérica, resultó útil la lectura de los trabajos de Paternina y Gamboa (1999), acerca de Colombia, y Rubilar (2007) en lo referido a Chile, pues siendo aproximaciones generales cubren aspectos relativos al trabajo, prácticas espaciales y habitación.

\section{Metodología}

Se ofrece un análisis temporal comparativo que pone en relación las escalas regional y local para afinar el acercamiento a la exclusión habitacional de los gitanos. El propósito es comprender la diversidad espacial y temporal, en cuanto a la manifestación del problema y las maneras de resolverlo, determinando el peso correspondiente a los factores geográficos. La amplitud del sistema urbano estudiado obligó a recopilar, contrastar y sistematizar un considerable volumen de información fragmentada, dispersa e incompleta. El resultado es la puesta en marcha de un fichero de 160 barrios, con información numérica y cualitativa sobre el colectivo, abierto a la incorporación de nuevos datos. Además de utilizar las estadísticas disponibles desde 2007, y los datos catastrales, se procedió a la revisión bibliográfica, recogiendo con preferencia lo posterior al año 2000. La escasez de investigaciones locales específicas fue parcialmente solventada mediante fuentes hemerográficas, tomando en consideración sólo aquellas informaciones cuya veracidad pudo contrastarse por otros medios. El apoyo fundamental ha sido el reconocimiento sobre terreno, realizado en un $60 \%$ de las localidades estudiadas durante el año 2019, para efectuar recuentos. También Google Maps y Google Street View resultaron de gran ayuda. Siendo inabordable la realización sistemática de encuestas en un territorio tan amplio, se efectuaron entrevistas informales, de manera ocasional, a los residentes durante el trabajo de campo para confirmar ciertos extremos o recabar información cualitativa. 


\section{*.*vis revistainvi}

\section{Resultados}

\section{LA INSUFICIENTE ACCIÓN ESTATAL FRENTE AL BARRAQUISMO, DURANTE LA dictadura de Franco}

La sedentarización de los gitanos españoles arranca en el siglo XVIII y culmina a mediados del XX, antes que en países cercanos como Francia donde el abandono de la itinerancia sólo se generalizó durante la década de 1980 (Bergeon, 2014; Movimiento Contra la Intolerancia, s. f.). Fueron agrupándose en función del origen, pertenencia a clanes o maneras de ganarse la vida, allí donde había precios más bajos, o menor dificultad de establecimiento informal, buscando espacio anexo a las viviendas para desempeñar sus ocupaciones tradicionales como artesanos, vendedores y tratantes de ganado (Ramírez, 1967-68). La existencia de edificios vetustos y zonas degradadas les permitió establecerse en el interior de la ciudad histórica o más frecuentemente en sus arrabales, cuando no poblaron los suburbios formados a comienzos del siglo XX, entornos semirrurales apropiados para sus prácticas de socialización, y para el resguardo de carros y animales de tiro. En efecto, ciertas parcelaciones del extrarradio acogieron gitanos con anterioridad a la Guerra Civil, y especialmente después, en León (Las Ventas) y Palencia (El Cristo). Aún permanecen allí, habitando en la primera de esas ciudades más de un centenar de viviendas, casi todas casas terrenas llamadas en Castilla casas molineras (25-51 $\left.\mathrm{m}^{2}\right)$, con esquema sencillo de puerta y una o dos ventanas. Rehabilitadas o deterioradas, subsisten en entornos definidos hoy por la renovación, el macizamiento y una cierta sustitución social, al haber mejorado su posición relativa con el crecimiento urbano.

La fracción más desfavorecida del colectivo habitó chabolas, cuyo origen aparece asociado con los gitanos al menos desde 1937 en Gijón (Martínez y Vázquez, 2000, p. 23). Al multiplicarse fueron el germen de los bidonvilles en las ciudades de mayor dinamismo, durante la Posguerra Civil (décadas de 1940-50) y particularmente en tiempos del Desarrollismo (décadas de 1960-70). Surgidos en lugares marginales, tenían distintos orígenes (parcelaciones, fincas rústicas alquiladas, ocupación ilegal) y morfologías, según estuviesen compuestos por barracas sensu estricto, hechas con material de desecho, o bien autoconstrucción de ladrillo, sin rebasar normalmente los $20 \mathrm{~m}^{2}$ de superficie. Predominaban las pequeñas agrupaciones, excepto en las localidades principales (Oviedo, Gijón) que conocieron poblados de entre cincuenta y cien unidades (Mancisidor, 2014). En algunos slums espontáneos hubo yuxtaposición de alojamientos alternativos de urgencia (albergues y módulos prefabricados), que también configuraron nuevos asentamientos cuyas condiciones eran todavía muy desfavorables. Aún sobreviven algunos de tipo mixto, como Cueto en Santander y O Bao de Abaixo en Pontevedra (Casares, 2011). Allí los calés de origen español, en gran parte inmigrados, convivían con fracciones menores de payos (no gitanos). A ellos se sumaron ciganos portugueses huidos del reclutamiento para las guerras coloniales, quienes trabajaban en la construcción, obras públicas u otras faenas, ocupando a veces núcleos separados (Galán, 2016; Martínez, 2018; Martínez y Vázquez, 2000). 


\section{*.*vis revistainvi}

Chabolistas y familias que renunciaban a las formas de vida de los viajeros, accedieron ocasionalmente a viviendas públicas o de la Iglesia tras la Guerra del 36. Tenían carácter precario o muy modesto, caso de los popularmente conocidos como barrios de Corea, en León (oficialmente La Inmaculada, 180 viviendas) y Palencia (San Juanillo, en origen Francisco Franco, 600 viviendas), con vecindario diverso (Asociación de Vecinos de San Juanillo, 2016; Cazorla, 2010; Gaitero, 2003). Utilizaban fincas de borde urbano, situadas al otro lado del ferrocarril y en las inmediaciones del hospital respectivamente, lo cual ayudó a estigmatizar a los coreanos. En Palencia la morfología es mixta, con una fracción comparativamente mejor (casas en hilera de planta y piso) y otra más pobre (bloques de ladrillo de baja calidad), donde están las casi sesenta viviendas (40-50 $\left.\mathrm{m}^{2}\right)$ ocupadas hoy por romanís llegados secuencialmente. En León se trata de un agregado de casas molineras con patio, parte de ellas de autoconstrucción $\left(51-75 \mathrm{~m}^{2}\right)$, casi todas sustituidas o reformadas hoy. Si en principio carecía de urbanización, las sucesivas mejoras lo han dignificado e incluso revalorizado, haciendo de él una suerte de ciudad jardín humilde, donde quedan quince familias de etnia gitana (Sánchez, 2017).

En otros conjuntos construidos por iniciativa oficial hasta mediados de los años sesenta (barriadas y polígonos) fue aumentando la escala de intervención hasta llegar a mil viviendas (La Inmaculada en Burgos) o dos mil (Ventanielles en Oviedo), de entre 44 y $65 \mathrm{~m}^{2}$. Parte de su censo está hoy integrado por gitanos residentes de primera generación o, más frecuentemente, por aquellos llegados después como grupo de sustitución. A menudo son asentamientos segregados, cercanos a industrias, hospitales o cuarteles, instalaciones que en algún caso han sido recicladas favorablemente como el cuartel de Viriato (Zamora), ahora centro universitario. Salvo esas excepciones, continúan siendo los distritos más pobres de sus respectivas ciudades. Dentro de ellos, los gitanos sólo tienen visibilidad en Oviedo (cien viviendas frente al resto donde no llegan a cuarenta), pudiendo verse sus furgonetas estacionadas en los patios interbloques. Hay ejemplos singulares de marginación transitoria como el de La Barriada (La Virgen del Camino, León, 1962), núcleo de tipología rural donde ocupan residualmente las casas más deterioradas (20 familias en 2019), que contrastan vivamente con otros inmuebles enajenados y rehabilitados recientemente para destinatarios de renta superior (figura 2). 


\section{*.*vis revistainvi}

\section{Figura 2.}

Viviendas concedidas a gitanos en la fracción deteriorada de un conjunto de posguerra.

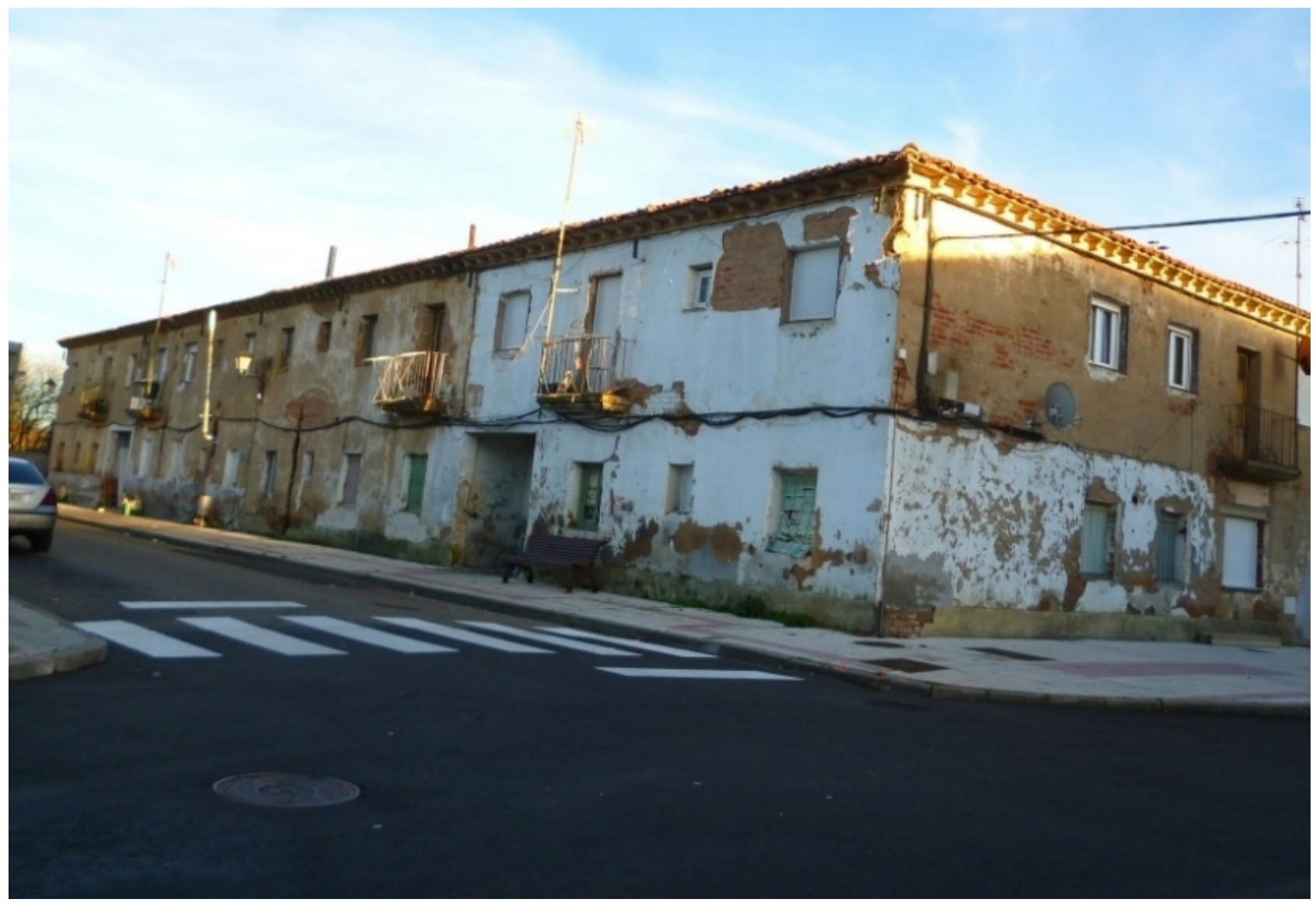

Fotografía del autor. 


\section{*.*vis revistainvi}

Todavía están en pie dos de los primeros poblados étnicos extraurbanos para realojo de chabolistas, con características de gueto, fórmula extendida luego. Uno se sitúa en O Portiño (La Coruña, 1963), al borde costero, cerca de la refinería de petróleos y el vertedero, hoy sellado. Contaba inicialmente con cuarenta y cuatro casas-barracón de cemento (35-55 $\left.\mathrm{m}^{2}\right)$, en disposición rectangular, con patios traseros y habitaciones interiores ciegas (Ayuntamiento de A Coruña, 2016; García, 2017; Pérez, 2003). Posteriormente se incorporaron viviendas normalizadas de Cáritas pero también alojamientos informales, resultando un núcleo cercano a las ochenta unidades. Otra experiencia pionera tuvo lugar en O Bao (Pontevedra), mediante el proyecto experimental del arquitecto César Portela (1970) para siete viviendas exentas sobre pilares, con planta y piso alto en forma de carromato (156-163 $\mathrm{m}^{2}$ ); finalmente se utilizó cubierta a dos aguas, y los bajos fueron cerrados, provocando una distorsión de la idea inicial agudizada después al sumarse construcciones precarias (Portela, s. f.).

En otro orden de cosas el tramo final de la Dictadura aportó, entre los años centrales de las décadas de 1960 y 1970, una nueva generación de polígonos residenciales Open Planning. Hoy les llamamos "desarrollistas", por el contexto dentro del cual fueron concebidos, aunque en no pocos casos su urbanización y ocupación se produjeron o fueron concluidas durante la Democracia. Parte de ellos contenía porcentajes variables de vivienda social en construcción estandarizada, donde tuvieron cabida pequeños contingentes de gitanos entre los primeros pobladores; sin embargo, su presencia sólo se consolidará en los años ochenta. Para los primeros afortunados, el traslado a un piso entrañaba la pérdida de espacio libre a la intemperie para almacenaje e interacción de grupo. Según relataron, y en consonancia con lo ya señalado por Paternina y Gamboa (1999), sus relaciones debieron recomponerse, para realizarlas de puertas adentro o en patios de vecindad compartidos. Algunos de ellos se convertirán en vendedores ambulantes, cuyas mercaderías serían guardadas en las viviendas o en camionetas, sustituyendo así progresivamente a los carros. 


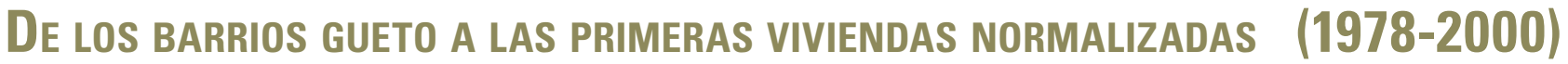

Las reformas democráticas trajeron consigo los Planes y Programas municipales de Erradicación del Chabolismo, en forma escalonada, a partir de 1981. Los más exitosos (Avilés, Gijón, entre otros) hicieron desaparecer esa lacra a la vuelta del siglo XXI, mediante la intervención de Ayuntamientos, Gobiernos Autonómicos y constructoras benéficas. Pero en otras ciudades la menor efectividad de las políticas frente al rebrote del barraquismo obligó a aprobar proyectos sucesivos hasta la actualidad, caso de La Coruña. Casi nunca se dio directamente el salto hacia la vivienda convencional sin recurrir previamente a soluciones temporales, que a veces se han perennizado (Botana, 2019). En ocasiones, la desmantelación o traslado de los focos de miseria resultó forzada a causa de los proyectos urbanísticos, vinculados por ejemplo a la apertura de los grandes almacenes El Corte Inglés, en La Coruña o León (Botana, 2020; Mahía, 2015). La localización de los nuevos barrios gueto dedicados exclusiva o fundamentalmente a gitanos fue extremadamente desfavorable, al menos en un tercio del total, por la cercanía a elementos repulsivos o el alejamiento (Tabla 1). Sus tamaños eran desiguales (7-52 unidades), aunque el 65\% de ellos no rebasaban las veinticuatro. Se emplearon barracones metálicos (ahora desaparecidos), módulos prefabricados de cemento como tipología dominante y casetas de madera, conviviendo ambas soluciones en algunos recintos mayores. Eran alojamientos individuales o pareados (sólo hubo bloques de dos plantas en Asturias), con problemas de aislamiento, ventilación e iluminación interior. 


\section{* revistainvi}

Tabla 1.

Barrios gueto (1970-2000)

\begin{tabular}{|c|c|c|c|c|c|c|}
\hline Ciudad & Barrio & Viv. & Fecha & Destrucción & Tipología & Entorno \\
\hline Avilés & $\begin{array}{l}\text { Ciudad Promocional } \\
\text { de Valliniello. }\end{array}$ & 36 & 1993 & 2007 & Bloques B+1 & Siderurgia \\
\hline \multirow[t]{2}{*}{ Burgos } & Bakinet & 23 & 1980 & 2006 & Casetas metal & $\begin{array}{l}\text { Industrial } \\
\text { abandonado }\end{array}$ \\
\hline & El Encuentro & 24 & 1993 & & $\begin{array}{l}\text { Casetas } \\
\text { madera }\end{array}$ & Cementerio \\
\hline \multirow[t]{2}{*}{ Ferrol } & Los Chaquetas & 20 & $?$ & & Modular & Grandes superficies \\
\hline & Narón-Freixeiro & 14 & 2000 & & Modular & Periurbano \\
\hline \multirow[t]{2}{*}{ Gijón } & San Juan & 20 & 1982 & 1997 & Modular & Periurbano \\
\hline & $\begin{array}{l}\text { Ciudad Promocional } \\
\text { Tremañes }\end{array}$ & 10 & 1971 & 1997 & Modular & Periurbano \\
\hline \multirow[t]{3}{*}{ La Coruña } & O Portiño & 44 & 1965 & & Barracones & $\begin{array}{l}\text { Vertedero } \\
\text { regenerado }\end{array}$ \\
\hline & A Pasaxe & 30 & 1984 & & Modular & $\begin{array}{l}\text { Industrial } \\
\text { abandonado }\end{array}$ \\
\hline & Penamoa & 50 & 1984 & 2012 & Modular & Refinería / petróleo \\
\hline \multirow[t]{2}{*}{ León } & Las Graveras & 14 & 1993 & & $\begin{array}{l}\text { Casetas } \\
\text { madera }\end{array}$ & Cárcel \\
\hline & Llanos de Nava & 7 & 1993 & & $\begin{array}{l}\text { Casetas } \\
\text { madera }\end{array}$ & Hospital \\
\hline Lugo & Nazareth (Carqueixo) & 40 & 1988 & Parcial & Mixta & Vertedero \\
\hline $\begin{array}{l}\text { Miranda } \\
\text { Ebro }\end{array}$ & Desconocido & $?$ & 1981 & 1988 & Modular & Río \\
\hline Oviedo & El Cascayu & 16 & 2000 & Parcial & Bloques B+1 & Grandes superficies \\
\hline
\end{tabular}




\begin{tabular}{|c|c|c|c|c|c|c|}
\hline Ciudad & Barrio & Viv. & Fecha & Destrucción & Tipología & Entorno \\
\hline & Piedramuelle & 16 & 1997 & 2016 & Bloques B+1 & Vertedero \\
\hline & Sierra Granda & 36 & 1981 & & Modular & Industrial \\
\hline Palencia & Cementerio & $?$ & 1996 & 2003 & Modular & Cementerio \\
\hline Ponferrada & Barrio Nuevo & 35 & 1988 & & Modular & Río \\
\hline \multirow[t]{2}{*}{ Pontevedra } & O Bao de Arriba & 7 & 1970 & & Unifamiliar & Periurbano \\
\hline & O Bao de Abajo & 10 & $?$ & & Modular & Periurbano \\
\hline \multirow[t]{3}{*}{ Santander } & Alday Camargo & 21 & 1992 & 2018 & Modular & Periurbano \\
\hline & Cueto Serpemar & 24 & 1990 & Parcial & Modular & Canteras \\
\hline & La Cavaduca & 52 & 1983 & 2007 & Modular & Periurbano \\
\hline Torrelavega & Sierrapando & 8 & 1998 & 2015 & Modular & Periférico \\
\hline Zamora & Rabiche & 20 & 1991 & & Unifamiliar & Periférico \\
\hline
\end{tabular}

Fuente: elaboración propia a partir de fuentes hemerográficas, trabajo de campo, Google Maps y Google Street View.

El catastro permite precisar el espacio habitable por familia en los núcleos que se conservan: $60 \mathrm{~m}^{2}$ de promedio y 70 en las cabañas de madera, más los patios y terrenos bajo porche. La manera de agrupar las construcciones varía según la disponibilidad de suelo y la existencia o no de un diseño urbanístico que tenga en cuenta los medios de vida y los patrones de socialización. Hay composiciones lineales, apiñadas y regulares, ordenadas en cuadro o vías paralelas, cuando se trata de proyectos mejor planificados como los de Sierra de Granda (Oviedo), Ciudad Promocional de Valliniello (Avilés), El Encuentro (Burgos) y el Cascayu (Oviedo) (Agulló et al., 2004; Gutiérrez, 2011; Martínez y Vázquez, 2000). Aun siendo iniciativas de apartheid, algunos disponen de carboneras, patios-almacén semicubiertos, incluso escuela o iglesia, y el de Sierra de Granda está articulado por una vía verde, al extremo de la cual se sitúa el inmueble destinado a funciones colectivas (Ro.Ma., 2015). En otros lugares las carencias obligaron a realizar o al menos proyectar reformas posteriores, como la del arquitecto Santiago Cirujeda (2007) para introducir servicios comunes en Penamoa (La Coruña) (García, 2011). Sea como fuere, el grupo se apropió del espacio para recuperar sus formas de vida tradicionales (Paternina y Gamboa, 1999) (figura 3). 


\section{繰 revistainvi}

Figura 3.

Plantas de barrios gueto: pabellones en formación rectangular (1), afrontados con verde intermedio (2), adaptados a las curvas de nivel (3) y en hileras compactas (4).
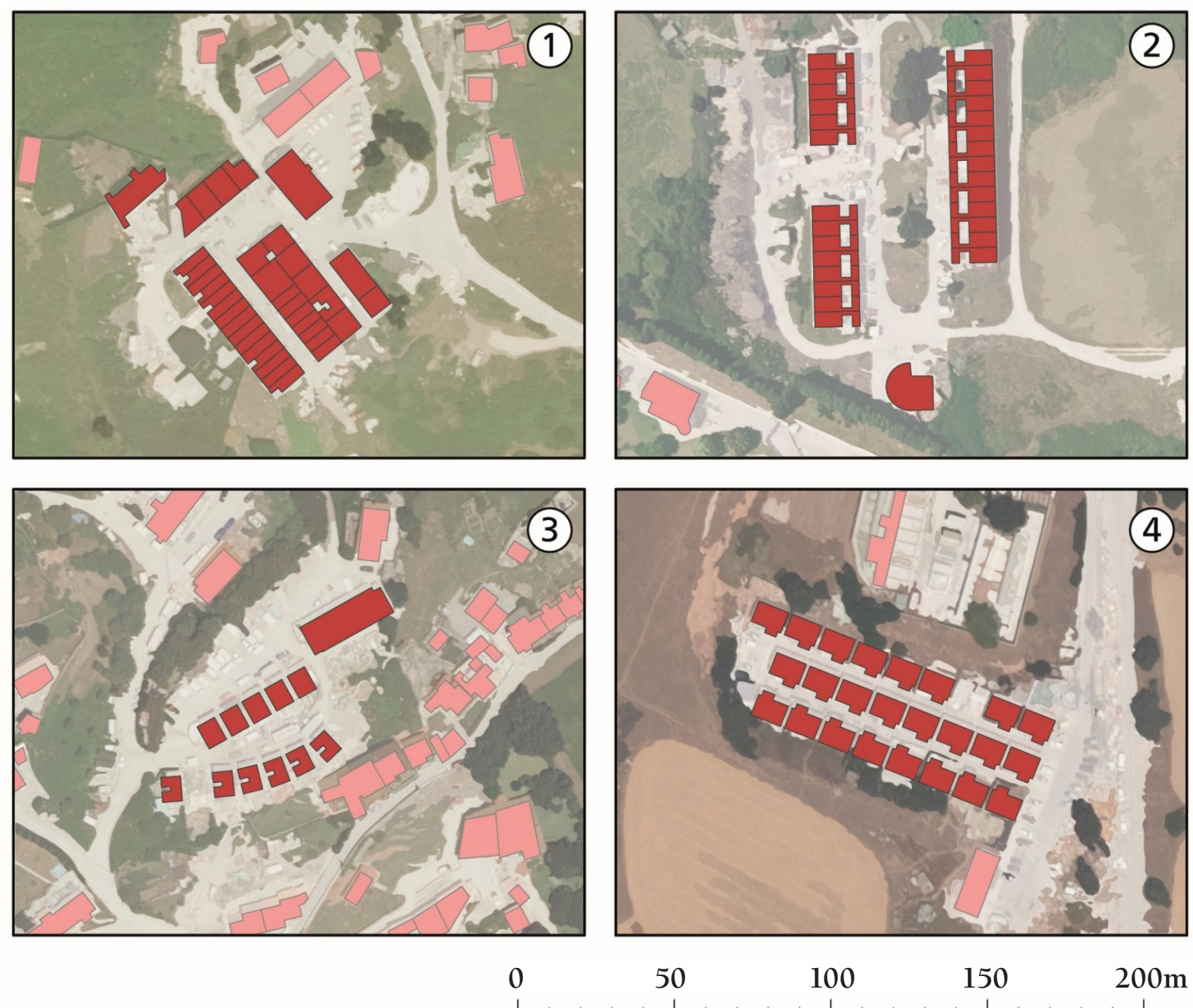

Fuente: Google Maps. Elaboración propia. 
La imagen de los poblados está muy determinada por la acumulación (en su interior o inmediaciones) de chatarra o materiales de desecho, y desperdicios cuando se carecía de servicios urbanos. El aspecto de conjunto fue perdiéndose a menudo con el añadido de excrecencias informales a base de chabolas, autoconstrucciones o, a veces, caravanas y furgonetas habitadas, por ejemplo en Serpemar (Santander) (Sellers, 2009). Los remolques suelen estar asociados con movimientos de radio corto propios de los vendedores ambulantes y feriantes, aunque no siempre. Esos desarrollos se yuxtaponen al núcleo original o forman otro aparte, ganan terreno al aire libre para depositar mercancías o enseres, pero su espontaneidad suele incrementar el hacinamiento o la insalubridad. Con el tiempo, al mejorar los ingresos de una parte del colectivo gracias al comercio en los mercadillos, las necesidades de vivienda y espacios para almacenaje sólo resultaban compatibles con los campamentos de mejores condiciones. Al contrario, la precariedad del resto y la vulnerabilidad de los residentes más desfavorecidos crearon caldo de cultivo para la venta de drogas.

El comportamiento posterior pone de relieve dinámicas muy diferenciadas. Respondiendo a su carácter transitorio, un tercio de los barrios gueto desaparecieron por completo, debido a sus deficiencias o por imperativo de las nuevas vías de circunvalación (Ayuntamiento de A Coruña, 2016; Botana, 2020). Los grandes parecen haber sido removidos más fácilmente y su eliminación no es ajena al aumento de valor de las áreas inmediatas, con las que resultan incongruentes al aparecer promociones residenciales de cierto nivel y malls (Alvear, 2009). Si los contornos no han variado sustancialmente es más fácil que el asentamiento subsista, la intervención gubernamental pueda mejorar su aspecto y dotaciones, o demoler progresivamente los módulos en peor estado y trasladar a los afectados. Pero otros vecinos permanecen, o retornan familias que abandonan los pisos sociales y arriban nuevos efectivos, de manera que la mayoría de los habitáculos restantes permanecen en uso, cuando no sobre ocupados, por lo que, en el peor de los casos, el conjunto puede abigarrarse y agudizar sus deficiencias, mereciendo la consideración de chabolista (Travesí, 2012) (figura 4). 


\section{粼 revistainvi}

Figura 4.

Barrio gueto de borde fluvial.

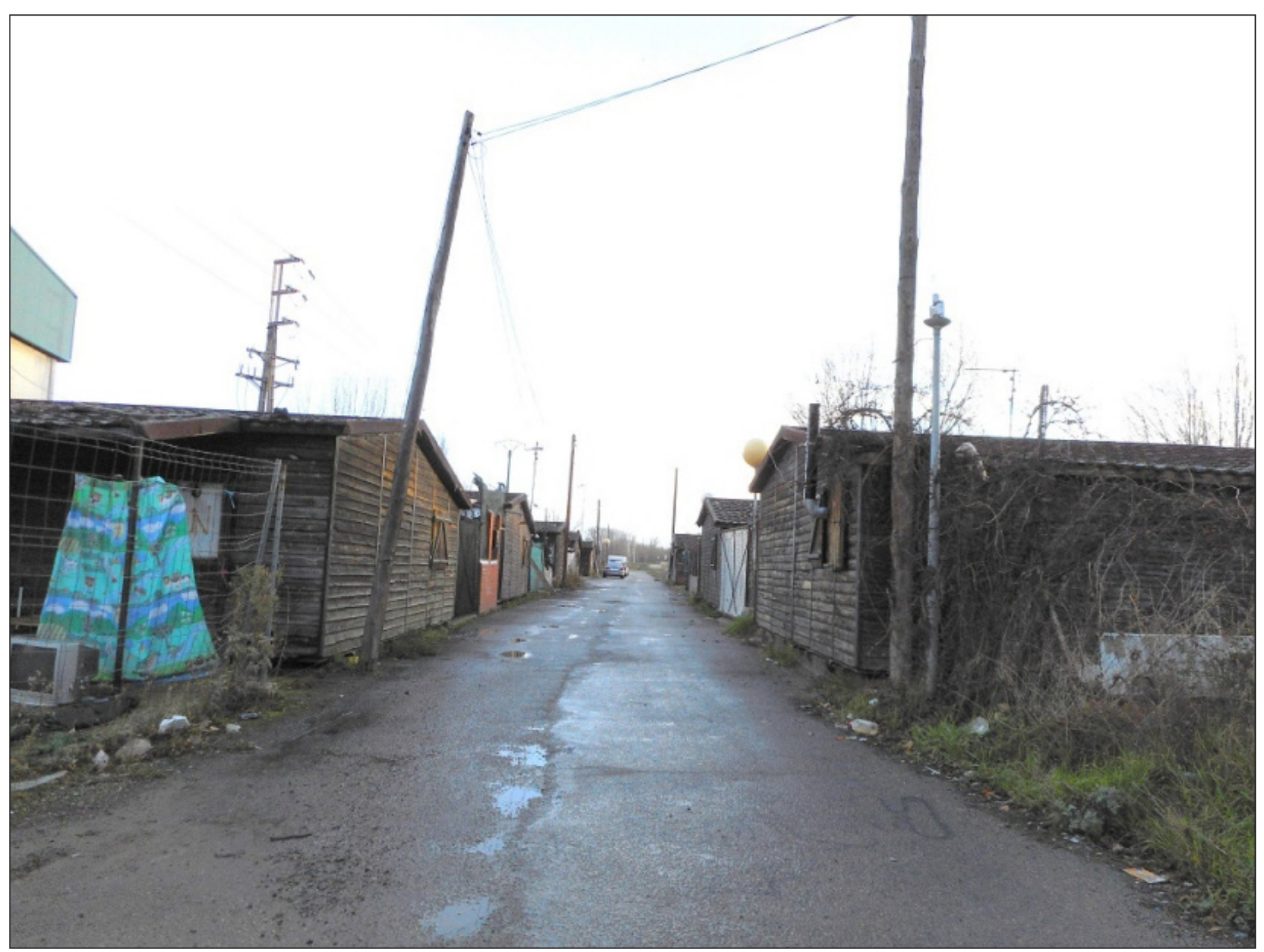

Fotografía del autor. 


\section{*.*vis revistainvi}

Hubo otras maneras de solventar el déficit habitacional, caso de As Rañas (La Coruña) donde los propios interesados compraron suelo barato intersticial próximo a autopistas y zonas industriales, para promover un núcleo de autoconstrucción que frisa la treintena de viviendas $\left(62-126 \mathrm{~m}^{2}\right.$ ) (Ayuntamiento de A Coruña, 2016; Peña, 2017). Parte de ellas, que son de planta y piso e incluso corredor, fueron mejoradas por sus habitantes según proyecto del ya mencionado Santiago Cirujeda (García, 2011; López, 2019a). Ocasionalmente la Administración buscó otras fórmulas, ya sea temporales -como la adquisición de viviendas antiguas para efectuar realojos (La Cerámica, Palencia)- o definitivas. Entre ellas la edificación de veinte casas adosadas con dos alturas $\left(100 \mathrm{~m}^{2}\right)$ y una satisfactoriedad constructiva muy superior a los módulos, en Rabiche (Zamora).

Como ya dijimos, el paso a la vivienda normalizada se dio, sobre todo desde los años ochenta, mediante pisos sociales. De promoción pública o protección oficial, según localidades, estos suman por regla general cantidades reducidas, en polígonos y zonas de crecimiento como Vite y Fontiñas (Santiago de Compostela), Cazoña (Santander), Río Vena (Burgos), Riaño (Langreo) y Otero (Oviedo). Proyectados entonces o heredados del planeamiento previo, son espacios con buen nivel de urbanización y al menos equipamientos básicos, donde los gitanos suelen ocupar las márgenes (Medina Saiz, 2000). Cuestión diferente es la elementalidad de la arquitectura y el carácter básico de los apartamentos, habiendo ejemplos de mala calidad y deterioro precoz entre los cuales se destacan el Grupo Orfeón Arandino (Aranda de Duero) o el polígono de Vite que hubo de ser rehabilitado ("Barrio de Vite", s. f.). Los signos externos de su presencia ya no estarán dominados por los locales de Cáritas o el Hogar de la Esperanza sino también por las iglesias evangélicas, abiertas asimismo en ciertos barrios gueto. La Administración logró afincar los calés, de manera excepcional, en distritos más céntricos (La Doblada en Vigo, El Zapatón en Torrelavega), llegando incluso a barrios de clase media baja en Oviedo (El Campillín), lo cual marcó un hito en la democratización del país.

El binomio mezcla étnica-diseminación es la clave del éxito, pero su efecto se pierde al concentrar rentas bajas y contingentes abultados de gitanos. Eso sucede en el polígono de La Vega (Armunia, León, 1983), donde la dureza de la arquitectura prefabricada (bloques en greca de hasta tres plantas, sobre pilares) se ve compensada por la amplitud de los pisos ( $89 \mathrm{~m}^{2}$ en su mayoría) y una composición abierta con patios ajardinados. Pero la situación periférica (entre el cuartel de la Guardia Civil y una industria química), el sucinto equipamiento comercial y un volumen de ciento diez viviendas habitadas por gitanos, en convivencia con inmigrantes y españoles, dan como resultado el área más pobre y peor valorada del municipio, cuya renta por habitante en 2016 representaba poco más de un tercio que la del distrito más acomodado, según el INE .

$1 \quad$ En febrero de 2020 podía adquirirse allí un piso por menos de 415 Euros $/ \mathrm{m}^{2}$, según el portal inmobiliario MilAnuncios.com, precio casi siete veces inferior al de las viviendas de segunda mano en el centro. 


\section{LA DIFICULTAD DE UNA INTEGRACIÓN PLENA: AVANCES Y PERSISTENCIAS DEL PASADO (2001-2020)}

Durante el tramo inicial del siglo XXI el colectivo pierde homogeneidad debido a su jerarquización económica. La posición más desahogada de ciertos grupos dedicados al comercio en los mercadillos, o a la economía irregular, les ha permitido buscar techo por sí mismos; otros se ven obligados a ello, aunque sus recursos sean limitados, al ralentizarse las inversiones públicas con la crisis de 2008 (Fundación Secretariado Gitano, 2016). Su cuantía también varía conforme a la orientación de las políticas seguidas en las distintas regiones y municipios, cuya efectividad depende de las diferentes condiciones de partida. Lo habitual es ofrecer pisos vacantes del fondo heredado y vivienda nueva, promovidos por el organismo competente de cada Comunidad Autónoma (VIPASA -Vivienda del Principado de Asturias- GESVICAN -Gestión de Viviendas e Infraestructuras de Cantabria, IGVS -Instituto Galego da Vivienda e Solo-) o por los Ayuntamientos. Por razones obvias es más frecuente el alquiler que la propiedad, adquirida con apoyo (Díez, 2007)². Avilés, Lugo y Torrelavega han comprado o alquilado viviendas usadas para ese fin, y ayudado (al igual que otras ciudades) a las familias que arriendan pisos particulares (Arminio, 2019). En términos comparativos la mayor inversión se efectuó en Asturias, donde 5,6 por cada 10 viviendas eran de alquiler protegido en 2015 (1,2-2,5 en las otras regiones) (figura 5). Sólo Castilla y León tenía entonces como régimen de tenencia dominante la propiedad ( $57 \%$ del total), y allí las viviendas de iniciativa oficial totalizaban un 35\%.

2 El alquiler medio en Asturias era de 82,83 euros en 2018 (Vipasa, 2018). 


\section{* revistainvi}

Figura 5.

Viviendas protegidas de última generación.

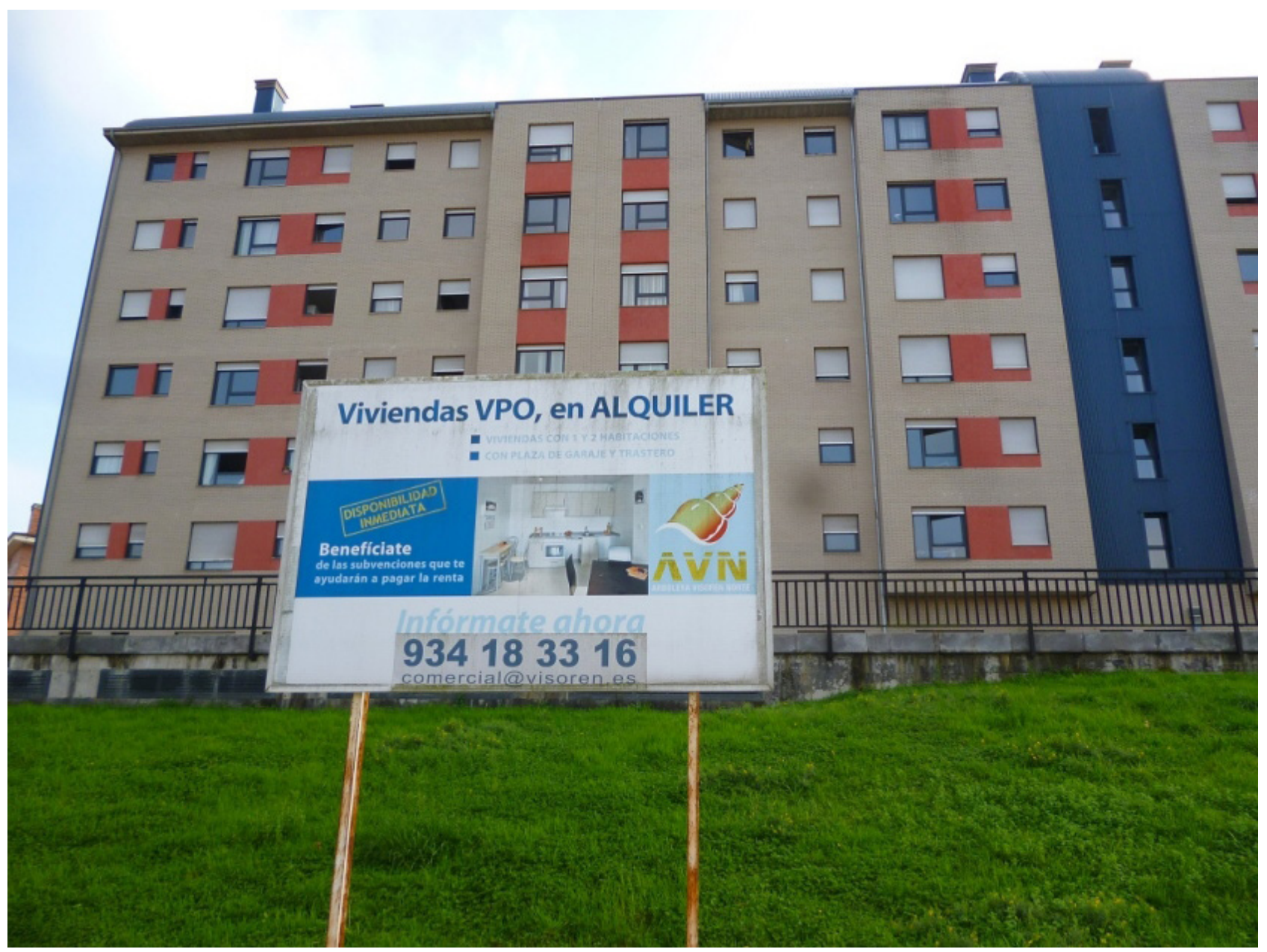

Fotografía del autor. 


\section{*.*vis revistainvi}

La promoción pública y el acceso de las familias con suficiente capacidad adquisitiva al mercado libre permiten hablar de una situación bastante satisfactoria en ciudades como Gijón y Santiago de Compostela. Son, también, destacados ejemplos de dispersión, con poblaciones repartidas entre los barrios tradicionales y los desarrollos urbanos más recientes (Méndez y Taboada, 2012). Entre 2007 y 2015 la mitad de los municipios estudiados pasaron a tener distribuciones más armónicas de sus efectivos, pero el resto avanzó hacia una mayor concentración, sin que puedan establecerse correlaciones directas entre esas dinámicas contrapuestas y el aumento o la disminución del número de viviendas ocupadas por gitanos.

Por regla general ganaron participación los nuevos espacios residenciales y polígonos, procedentes a veces de la etapa inmediatamente anterior. Monteporreiro (Pontevedra), Nuevo Santuyano (Mieres), Abella (Lugo) y La Corredoria (Oviedo) son los más característicos, así como los ya citados Cazoña (Santander) y Fontiñas (Santiago). Las viviendas concedidas a miembros de esa etnia, de forma consensuada y no sin resistencia de otros vecinos, varían entre 40 y 62, excepto en Cazoña (140) y Corredoria-Carisa (252, con dimensiones de 50-55 y 90-94 $\mathrm{m}^{2}$ en los pisos más recientes). Algunos polígonos presentan cierto interclasismo y zonificación social horizontal, de modo que los romanís suelen habitar las parcelas con menor valor inmobiliario, compartiéndolas con otros españoles y extranjeros de baja capacidad adquisitiva. Puede hablarse entonces de nuevos guetos, especialmente si hay reubicación de chabolistas (Martínez, 2018; Montañés, 2008).

El otro centro de atención se sitúa en las zonas de asentamiento previas, sean barrios tradicionales o conjuntos de viviendas sociales, heredados del franquismo o los años de la transición democrática. El acceso a los pisos desocupados de titularidad pública es organizado y espontáneo a los otros, facilitado por la obsolescencia de algunos distritos. De hecho, su deterioro ha obligado a aplicar medidas regeneradoras bajo la figura de las ARI (Áreas de Rehabilitación Integral) en Burgos, Ferrol y Santiago, o al amparo del programa europeo Urban (Oviedo). Este insiste más en los espacios públicos y equipamientos, mientras las ARI intervienen en la envolvente de los edificios, su accesibilidad y las redes técnicas. Vinculada a la depauperación y envejecimiento no ha estado ausente la ocupación de pisos por familias gitanas, en las Sindicales de San Pablo (Ferrol) y sobre todo en las Casas Baratas municipales de la misma localidad (Recimil), donde en 2019 había un centenar de viviendas afectadas, el 10\% del total (Díez, 2017; López, 2019).

La búsqueda de soluciones por los propios interesados guarda una relación ambivalente con la crisis de 2008: ésta redujo los precios de venta, favoreciendo a un estrato minoritario, pero en contrapartida incrementó la cuantía de los alquileres en las ciudades mayores, para perjuicio de la generalidad. Son sobre todo las capas mayoritarias las que se dispersan por el área central, suburbios históricos, barrios de posguerra o zonas en expectativa de transformación, donde existen edificios vetustos, incluso ruinosos, ocupadas al completo, o viviendas rechazadas por otros demandantes (bajos a la calle, bajos interiores, sotabancos). Su estancia puede ser temporal, hasta que avanza la rehabilitación o gentrificación, en algunas arterias del centro de Santander (Observatorio de Salud Pública de Cantabria, 2012). También en calles muy prestigiosas de Oviedo y León ciertos propietarios de inmuebles históricos permitieron la entrada temporal de gitanos, para ahuyentar a 


\section{*.*vis revistainvi}

los inquilinos de rentas bajas y posibilitar el derribo o restauración a fin de obtener apartamentos caros ${ }^{3}$. Si el barrio es más estable por su peor localización, pueden permanecer indefinidamente, sobre todo en las poblaciones pequeñas donde las perspectivas de renovación del caserío son escasas, salvo declaración de ruina. Ciudades menguantes como León, Mieres y Langreo, sometidas a reconversiones minero-industriales, ofrecen una enorme cantidad de viviendas e inmuebles donde establecerse, ya sea completos, desocupados o en vías de abandono, además de espacios residuales como calles particulares o núcleos aislados de vivienda obrera histórica (Tomé, 2019).

Así retornan el alojamiento inadecuado y el hábitat insalubre, sumándose al problema pendiente de los barrios gueto, cuya edad llega a superar el cuarto o hasta el medio siglo. En 2020 quedan alrededor de una decena de viviendas en Serpemar (Santander), una veintena en Narón (Freixeiro) o Sierra de Granda (Oviedo) y más del doble en El Encuentro (Burgos) y A Pasaxe (La Coruña), por citar algunos. Este último parece ser hoy el de peor habitabilidad por el hacinamiento y la acumulación de materiales de desecho, pese a los derribos parciales y realojos (Malvido, 2020). Al menos en dos ciudades pudo comprobarse que algunas familias no residen en los núcleos, sino que los utilizan como almacén de mercancías al aire libre, a modo de zona franca. Entre tanto han permanecido o aparecen, en Galicia y León, nuevos asentamientos informales. A excepción del de Penís (Vigo), algo mayor, a cobijo de un eucaliptal, los demás son pequeñas agrupaciones de 2 a 7 chabolas y a veces remolques, en baldíos laterales a las vías de comunicación, o parajes degradados por la presencia de fósiles urbanos (Pita, 2019). Guardan alguna conexión con la colonia portuguesa, sólo numerosa en Orense (61 viviendas en 2015). Para esa fecha únicamente Asturias llevaba un registro detallado de los efectivos procedentes del Este, 9,2 \% del total nacional (Fundación Secretariado Gitano, 2016). Oviedo y Avilés (79 y 46 viviendas, respectivamente) son los principales focos, con poblamiento muy diseminado incluso en distritos bien situados.

Ahora bien, la penuria ya no define universalmente el hábitat gitano, pues el ascenso económico ha sostenido el salto de algunas familias o clanes a viviendas de cierta categoría e incluso chalets. Es forzoso reconocer el papel que en ciertos medios viene desempeñando el tráfico de drogas, tradicionalmente coincidente con enclaves marginales, fácilmente asequibles en automóvil; caso de Las Llamas (Zamora), donde los protagonistas se afincaron en casas molineras de posguerra $\left(43-59 \mathrm{~m}^{2}\right.$ ) abandonadas por los ganaderos (Arizaga, 2011). El esquema se mantiene actualmente en Freixeiro (Narón), agrupación lineal de una veintena de edificios en paraje muy bien comunicado de la periferia de Ferrol, próximo a grandes superficies comerciales y promociones residenciales recientes. Pero en otros casos la venta se disocia del domicilio de los traficantes o éste cobra una expresión espacial novedosa. En la propia comarca ferrolana pueden verse recintos cerrados (al menos parcialmente) mediante muros de cemento y verjas, versión peculiar de las gated communities con nombres singulares (Las Chaquetas, Los Peinados, Lupín, Rocky). Son agregados de casetas modulares, autoconstrucción y en los dos últimos mencionados también chalés (7-20 viviendas), situados cerca del cementerio (Catabois), grandes comercios (Decathlon) e industrias (Inditex), con buen acceso. La prensa reporta redadas en esos lugares al menos entre 2008 y 2019 (López, 2016).

3 Esa transitoriedad parece explicar la reducción de la cifra de asentamientos entre 2007 y 2015, en Langreo, Santander y Torrelavega. 
Tal y como recoge la figura 1, nueve ciudades incrementaron en más de un 20\% el número de viviendas habitadas por gitanos, entre 2007 y 2015, frente a cinco que experimentaron pérdidas por encima del mismo valor $^{4}$. Las mayores ganancias (64\% en Avilés, 78\% en Oviedo y 193\% en Santiago de Compostela) son fáciles de explicar pues las dos últimas son capitales autonómicas y las dos primeras pertenecen a la región que más ha invertido en viviendas protegidas, además de reunir contingentes abultados. Los aumentos moderados (20-50\%) se dan en localidades de rango inferior, ciudades pequeñas (Langreo, Mieres, Orense, Ponferrada, Pontevedra) o en los municipios periféricos de las grandes (Camargo), con una casuística diversa. Parte de ellas están estancadas o en declive, con un importante stock de viviendas vacantes, mientras que en Orense parece decisiva la presencia de portugueses y en Mieres y Pontevedra es destacable el peso de la iniciativa oficial. Las pérdidas de menor cuantía (21-29\%) se dan tanto en Shrinking Cities (León, Lugo) como en las mayores aglomeraciones (Vigo), aquí seguramente por efecto de los precios, mientras que en Poio (periferia de Pontevedra) el desencadenante sería la disminución del censo en el barrio gueto de $\mathrm{O}$ Bao. Benavente experimenta la mayor caída, relacionada con su estancamiento o la falta de vivienda pública, y en el resto del sistema urbano la variación resulta poco significativa. 


\section{*.*vis revistainvi}

Figura 6.

Tramas urbanas de casas molineras en revalorización.

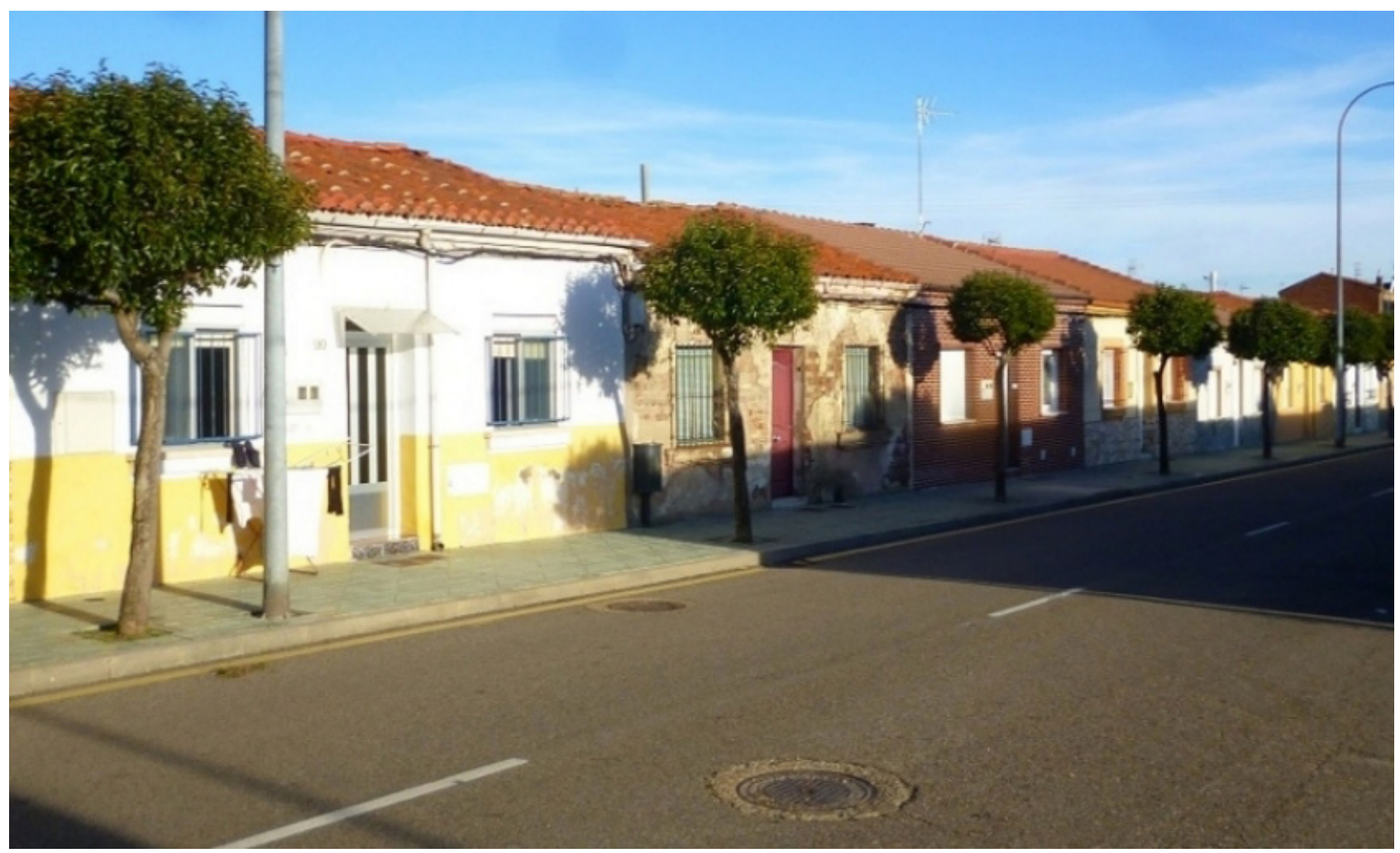

Fotografía del autor. 


\section{*.*vis revistainvi}

\section{Conclusiones}

La segregación socio espacial de los gitanos ha sido, según las épocas y las lógicas urbanísticas de las distintas ciudades, una experiencia separada (chabolismo, barrios gueto) o compartida con otros grupos de rentas bajas (pisos sociales); normalmente inmigrantes, que en los años sesenta y setenta procedían de la España pobre, mientras ahora vienen de otros países. Hoy se avanza hacia una realidad progresivamente más compleja, con dinámicas bipolares. En términos generales, puede afirmarse que la vivienda ya no es el factor clave de discriminación para las más amplias fracciones del colectivo. La experiencia demuestra que las cosas sólo han cambiado suficientemente allí donde hay voluntad gubernamental y conjunción entre políticas regionales y locales, dando como resultado una presencia más difusa y mayor estabilidad residencial. Las provincias donde la intervención tiene mayor alcance suelen ser igualmente las que aportan más información al respecto. Pero estamos ante un proceso a varias velocidades, que también se estanca o reproduce situaciones del pasado. La inhibición gubernamental, o el declive de algunas ciudades medias o pequeñas, favorece la cronificación de las lacras, la representación social negativa y la estigmatización de un grupo que, sin embargo, se estabiliza o decrece. Normalmente los focos de miseria continúan situados en los barrios gueto con añadidos de autoconstrucción precaria y en las barriadas marginales de vivienda social (que en la zona de estudio no mantienen una relación directa con los inmigrados del Este). De otro lado está el problema de las familias que se desplazan dentro de la ciudad tradicional, para habitar pisos de baja calidad o deteriorados, de forma provisional o duradera. Entre el apartheid y la normalidad, los contextos locales determinan una casuística muy variada, no exenta de paradojas: desde los municipios en los cuales los gitanos han logrado ser alcaldes de barrio (Oviedo) y concejales (León), hasta aquellos donde una forma elemental de gentrificación llega a barriadas franquistas de vivienda unifamiliar, en las cuales siempre residieron (Figura 6). La presencia ocasional de vehículos de alta gama en zonas de hábitat informal corrobora que estamos ante realidades cuya lectura no siempre resulta fácil. Verosímilmente, y en el actual contexto de crisis agravado por la pandemia, la menor inversión pública hará mella, mientras que en el sector privado los desahucios tenderán a cobrar relevancia; pero por el momento parecen carecer de ella, frente a hechos como la resistencia de los propietarios de viviendas en buen estado a tomar calés como arrendatarios. 


\section{Referencias bibliográficas}

Agulló, T., Cabo, J., Capa, M., Rodríguez, J., y Sánchez, C. (2004). Erradicación del chabolismo e integración social de los gitanos en Avilés. Ediciones de la Universidad de Oviedo.

Alvear, P. (2009, 24 de enero). El Cascayu es un gueto. El Comercio. https://www.elcomercio.es/gijon/20090124/ oviedo/cascayu-gueto-guetos-destruyen-20090124. $\underline{h t m l}$

Amador, M. (2018). Quand la population fait le bidonville. Le cas des gitans de la Campagne Fenouil à Marseille (1960-1998). Hommes \& Migrations, (3)3, 158-167. https://doi.org/10.4000/hommesmigrations.6771

Arizaga, S. (2011, 10 de julio). Los vecinos denuncian abandono, chabolismo y trasiego de toxicómanos en Las Llamas. La Opinión de Zamora. https://www.laopiniondezamora.es/zamora/2011/07/10/vecinos-denuncian-abandono-zona-piden-1952305.html

Arminio, J. I. (2019, 3 de enero). Torrelavega compra una casa para erradicar el chabolismo en Sierra Pando. El Diario Montañés. https://www.eldiariomontanes.es/torrelavega/ayuntamiento-compra-casa-20190103203221-ntvo.html

Artoni, C. (2015). Les défis de la communauté gitane en Espagne, le pari des "chavales". BAB El Med. https://www.babelmed.net/article/3618-les-defis-de-la-communaute-gitane-en-espagne-le-pari-des-chavales/

Asociación de Vecinos de San Juanillo. (2016). Historia. http://www.asociacionsanjuanillo.es/cronologia/
Ayuntamiento de A Coruña y Arquitectos sin Fronteras (2016). Plan de acceso ao hábitat digno para as personas habitantes dos asentamentos precarios na cidade da Coruña. https://www.coruna.gal/descarga/1453602899296/ PAHD Plan-acceso-ao-habitat-digno.pdf

Barrio de Vite (Santiago de Compostela). (s. f.). Xunta de Galici. https://ari-igvs.xunta.gal/es/node/154

Bergeon, C. (2014). La mobilité des familles tsiganes françaises à l'épreuve de la gestion politique de l'espace. Stratégies et résistances. Cybergeo : European Journal of Geography, art. 675. https://doi. org/10.4000/cybergeo.26310

Botana, C. (2019). Estudo dos asentamentos precarios na provincia da Coruña. Análise da situación, 2019. Deputación de A Coruña.

Botana, C. (2020). La promoción pública de segregación urbana. Crítica Urbana, (12), 17-20.

Casares, C. (2011, 23 de octubre). El poblado marginal de O Vao llega al medio siglo en un callejón sin salida. La Voz de Galicia. https://www.lavozdegalicia.es/noticia/pontevedra/2011/10/23/poblado-marginal-vao-llega-medio-siglo-callejon-salida/0003 201110P23C2991.htm

Caselles, J. F. (2013). Vivienda y pueblo gitano. En M. Hernández, Vivienda y exclusión residencial (pp. 269289). Universidad de Murcia.

Castro, A. (2007). Dos contextos locais à invisibilizaçao política: Discusión de torno dos ciclos de exclusión habitacional dos ciganos em Portugal. Cidades, Comunidades e Territorios, (15), 63-86. 
Castro, A. y Correia, A. (2008). Ciganos e precariedade habitacional: una aproximação à realidade em Portugal. En Actas do Seminário Internacional Ciganos, Territórios e Habitat ISCTE, 8 e 9 de abril de 2008 (pp. 31-45).

Cazorla, A. (2010). Fear and Progress. Ordinary Lives in Franco's Spain 1939-1975. Wiley- Blackwell.

Cingolani, P. (2016). Good romanian gypsy looking for a home. Revue Européenne des Migrations Internationales, 32(1), 59-78. https://doi.org/10.4000/remi.7645

Condon, L., Bedford, H., Ireland, L., Kerr, S., Mytton, J., Richardson, Z., y Jackson, C. (2019). Engaging Gypsy, roma and traveller communities in research: Maximizing opportunities and overcoming challenges. Qualitative Health Research, 29(9), 1324-1333. https:// doi.org/10.1177/1049732318813558

Delépine, S. (2007). Quartiers tsiganes. L'habitat et le logement des Roms de Roumanie en question. L'Harmattan.

Díez, F. (2007). La Cavaduca, Cantabria. Gitanos, Pensamiento y Cultura, (40-41), 28-30. https://www.gitanos.org/upload/05/84/40 41AyeryHoy.pdf

Díez, M. (2017). El barrio de Recimil. Un estudio de caso sobre las consecuencias sociológicas de la obsolescencia urbana. (Máster en Sociología aplicada, Universidade da Coruña).

Fundación Secretariado Gitano. (2007). Mapa sobre vivienda y comunidad gitana en España 2007. Ministerio de Vivienda, D’Aleph. https://www.gitanos.org/ upload/28/77/mapa01.pdf

Fundación Secretariado Gitano. (2016). Estudio-mapa sobre vivienda y población gitana 2015: informe septiembre de 2016. Ministerio de Sanidad, Servicios Sociales e Igualdad. https://www.mscbs.gob.es/ssi/familiasInfancia/PoblacionGitana/docs/INFORMECOMPLETO STUDIO-MAPA-VIVIE-Y P. G.pdf
Fundación Secretariado Gitano. (2016). Estudio-mapa sobre vivienda y población gitana 2015. Anexo 2 del informe: información desagregada por comunidades autónomas y provincias septiembre de 2016. https://www.mscbs. gob.es/ssi/familiasInfancia/PoblacionGitana/docs/ ANEX2MAPAVIVIEPOBLAGITANA.pdf

Gaitero, A. (2003, 27 de julio). La Inmaculada quiere salir del gueto. Diario de León. https://www. diariodeleon. es/articulo/afondo/inmaculada-quiere-salir-gueto/20030727000000671490.html

Galán, J. F. (2016, 25 de febrero). El programa de erradicación del chabolismo permitió realojar a 571 personas en Avilés. El Comercio. https://www.elcomercio.es/ aviles/201602/25/programa-erradicacion-chabolismo-permitio-20160225002443-v.html

García, R. (2011, 1 de febrero). El Concello contabiliza 168 familias en los 4 poblados chabolistas de la ciudad. La Opinión. https://www.laopinioncoruna.es/ coruna/2011/02/01/concello-contabiliza-168-familias-cuatro-25157203.html

García, R. (2017, 6 de septiembre). Tras medio siglo, O Campanario revive. La Voz de Galicia. https://www.lavozdegalicia.es/noticia/coruna/2017/09/06/tras-medio-siglo-campanario-revive/0003 201709H6C5991.htm

Greenfields, M y Smith, D. (2010). Housed Gypsy travellers, social segregation and the reconstruction of communities. Housing Studies, 25(3), 397-412. https://doi. org/10.1080/02673031003711022

Gutiérrez, B. (2011). Avilés, por una convivencia intercultural. Proceso y resultados del Plan de Erradicación del Chabolismo e integración social de los gitanos en Avilés, 1989-2011. Hábitat y Sociedad, (3), 133-150. https://doi.org/10.12795/habitatysociedad.2011.i3.08

Hernández, A. (1997). Análisis urbanístico de barrios desfavorecidos. Catálogo de áreas vulnerables españolas. Cuadernos de Investigación Urbanistica, (19), 1-104. 
Hernández, M., García, 0., y Gehrig, R. (2019). Situación social de la población gitana en España: balance tras la crisis. Observatorio de la Exclusión Social de la Universidad de Murcia. https://www.foessa.es/main-files/uploads/sites/16/2019/06/3.12.pdf

Legros, 0. y Vitale, T. (2011). Les migrants Roms dans les villes françaises et italiennes: mobilités, regulations et marginalités. Géocarrefour, 86(1). https://doi. org/10.4000/geocarrefour.8220

López, C. (2016, 11 de febrero). Cinco clanes locales lideran el narcotráfico en el norte de Galicia. La Voz de Galicia. https://www.lavozdegalicia.es/noticia/ferrol/ naron/2016/02/11/cinco-clanes-locales-lideran-narcotrafico-norte-galicia/0003 201602F11C2993.htm

López, C. (2019, 25 de mayo). No aguanto más, me voy de Recimil. La Voz de Galicia. https://www.lavozdegalicia.es/noticia/ferrol/2019/05/25/aguanto-dejo-recimil/0003 201905F25C1993.htm

López, E. (2019a, 30 de mayo). Cirujeda apuesta por recuperar el proyecto del poblado de As Rañas. Cadena Ser. https://www.cadenaser.com/emisora/2019/05/30/radio coruna/1559221291 743129.html

Macura, V. (1999). Housing, urban planning and poverty: problems faced by Roma gypsy communities with particular reference to central and eastern Europe. Council of Europe. https://doi.org/10.13140/RG.2.2.21293.64487

Mahía, A. (2015, 11 de julio). Penamoa, tres años después. La Voz de Galicia. https://www.lavozdegalicia.es/ noticia/coruna/2015/07/11/penamoa-tres-anos-despues/0003 201507H11C6993.htm

Malvido, G. (2020, 28 de septiembre). Cristina Botana: Los poblados chabolistas son producto del Concello, no de sus residentes. La Opinión. https:// www.laopinioncoruna.es/coruna/2020/09/28/ cristina-botana-poblados-chabolistas-son-23418249.html

Mancisidor, M. (2014, 9 de junio). Avilés pasa la página del chabolismo. La Nueva España. http://www.mundogitano.net/index.php/es/noticias/iberia/1688-asturias-aviles-pasa-la-pagina-del-chabolismo

Mapping For Change. (2017). Gypsies and travellers in London. https://mappingforchange.org.UK/2017/05/ gypsies-and-travellers-in-london/

Martínez, D. (2018, 12 de febrero). Las últimas chabolas de Cantabria. El Diario Montañés. https://www.eldiariomontanes.es/cantabria/ultimas-chabolas-cantabria-20180211185734-nt.html

Martínez, S. y Vázquez, J. A. (2000). La erradicación del chabolismo en Gijón. Análisis de su evolución y evaluación económica. Ayuntamiento de Gijón.

Medina, A. (2000). La promoción oficial en Santander (1955-1994). Estudios Geográficos, 61(239), 283-299. https://doi.org/10.3989/egeogr.2000.i239.530

Méndez, M. J. y Taboada, C. (2012). Igualdade de trato. Retos e respostas socioeducativas. Universidade de Santiago, Servicio de Publicaciones e Intercambio Científico.

Montañés, E. (2008, 28 de marzo). Gitanos, entre el trigo y la paja. ABC. https://www.abc.es/ espana/galicia/abci-gitanos-entre-trigo-y-paja-200803280300-1641751024471 noticia.html

Movimiento Contra la Intolerancia. (s. f.). Aproximación histórica al pueblo gitano. http://www.movimientocontralaintolerancia.com/html/denuncias2BL/puebloGitano/aproxHistorica2.htm

Nugent, C. (2018, 18 de junio). It's like we don't exist: London's gypsies stand up to be courted. The Guardian. https://www.theguardian.com/cities/2018/jan/18/ london-gypsies-counted-travellers-map-prejudice 
Observatorio de Salud Pública de Cantabria. (2012). Estudio sobre los determinantes sociales de la salud de la población gitana cántabra. Consejería de Sanidad y Servicios Sociales Observatorio de Salud Pública de Cantabria.

Paternina, H. y Gamboa, J. (1999). Los gitanos: tras la huella de un pueblo nómade. Nómadas, (10), 156-170.

Peña, A. (2017, 5 de agosto). El poblado de As Rañas suma chabolas mientras se desmantela el de A Pasaxe. El Ideal Gallego. https://www.elidealgallego.com/texto-diario/mostrar/2358363/poblado-as-ranas-suma-chabolas-mientras-desmantela-pasaxe

Pérez, R. (2003). Memoria del barrio de 0 Portiño. Boletín de la Oficina de Acción Solidaria

Pita, E. (2019, 4 de septiembre). La jueza ordena echar de Navia a treinta chabolistas para montar un gimnasio. La Voz de Galicia. https://www.lavozdegalicia.es/noticia/vigo/vigo/2019/09/03/jueza-ordena-echar-navia-30-chabolistas-montar-gimnasio/00031567535622303183573.htm

Portela, C. (s. f.). Viviendas comunidad gitanos (Campañó, Pontevedra)._https://www.cesarportela.com/ viviendas-para-comunidad-de-gitanos

Potot, S. (2016). La "question Rom" à l'echelle de la ville: gouvernance locale, pratiques informelles et pouvoir des acteurs faibles. L'Espace Politique, 29(2). https:// doi.org/10.4000/espacepolitique.3856

Poza, J. C. (2014). La vivienda como factor de integración social de familias chabolistas realojadas. (Grado en Trabajo Social, Universidad de La Rioja). https://reunir. unir.net/handle/123456789/2770

Ramírez, J. D. (1967 y 1968). Las profesiones gitanas. Pomezia, Boletín informativo de divulgación gitana, (21,24, 25 y 27$)$.

Ro.Ma, 0. (2015). Poblado gitano de La Granda. Arquitectura de Asturias. http://www.arquitecturadeasturias. com/obras/poblado-gitano-de-la-granda/
Rubilar, M. (2007). Los gitanos en Chile: de viajeros eternos a soñadores. Memoria chilena. http://www.memoriachilena.gob.cl/602/articles-123219_recurso_2.pdf

Sánchez, A. (2017). Corea, una historia paralela. Self Published.

Sellers, G. (2009, 3 de mayo). Los gitanos avisan de que no desalojarán las caravanas del poblado de Serpemar. El Diario Montañés. https://www.eldiariomontanes. es/20090503/santander/destacados/gitanos-avisan-desalojaran-caravanas-20090503.html

Tomé, S. (2019). Shrinking cities de tamaño medio: la ciudad de León, ¿Detroit española? En Crisis y espacios de oportunidad: retos para la geografía: libro de actas (pp. 837-851). AGE y Universidad de Valencia.

Travesí, R. (2012, 16 de abril). Fundación Lesmes plantea alquilar y no comprar los pisos para realojos. Diario de Burgos. https://www.diariodeburgos.es/noticial z3503d084-a8cf-f69f-70779a853c2f9e9f/20120416/ fundacion/lemses/plantea/alquilar/no/comprar/ pisos/realojos/

Vallvé, X. (2009). Estudio temático sobre la población gitana y la vivienda en España. Gabinet d'Estudis Socials, Centro de Referencia en España de la Agencia de Derechos Fundamentales de la Unión Europea.

Van Cleemput, P. (2008). Health impact of Gypsy sites policy in the UK. Social Policy and Society, 7(1), 103-117. https://doi.org/10.1017/S1474746407004046

Vipasa. (2018). Memoria de actividad 2018. http://www.vipasa.info/images/adjuntos/Actividad2018.pdf

Yeamreg, T. (2018). Stigmatisation, gentrification: les gitans de Perpignan laissés pour compte. Revolution Permanente. https://www.revolutionpermanente.fr/ Stigmatisation-gentrification-les-gitans-de-Perpignan-laisses-pour-compte

Ziomas, D., Bouzas, N., y Spyropoulou, N. (2011). Greece: Promoting the social inclusion of Roma. A Study of national policies. National Centre for Social Research. 


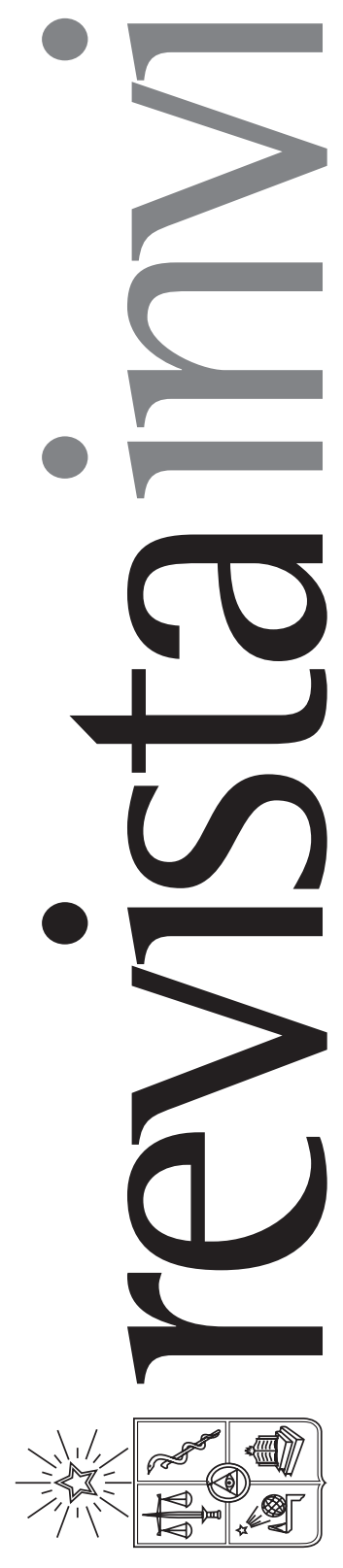

Revista INVI es una publicación periódica, editada por el Instituto de la Vivienda de la Facultad de Arquitectura y Urbanismo de la Universidad de Chile, creada en 1986 con el nombre de Boletín INVI. Es una revista académica con cobertura internacional que difunde los avances en el conocimiento sobre la vivienda, el hábitat residencial, los modos de vida y los estudios territoriales. Revista INVI publica contribuciones originales en español, inglés y portugués, privilegiando aquellas que proponen enfoques inter y multidisciplinares y que son resultado de investigaciones con financiamiento y patrocinio institucional. Se busca, con ello, contribuir al desarrollo del conocimiento científico sobre la vivienda, el hábitat y el territorio y aportar al debate público con publicaciones del más alto nivel académico.

Directora: Dra. Mariela Gaete Reyes, Universidad de Chile, Chile Editor: Dr. Luis Campos Medina, Universidad de Chile, Chile.

Editores asociados: Dr. Gabriel Felmer, Universidad de Chile, Chile.

Dr. Walter Imilan, Universidad de Chile, Chile.

Coordinadora editorial: Sandra Rivera, Universidad de Chile, Chile.

Asistente editorial: Katia Venegas, Universidad de Chile, Chile.

\section{COMITÉ EDITORIAL:}

Dr. Victor Delgadillo, Universidad Autónoma de la Ciudad de México, México.

Dra. María Mercedes Di Virgilio, CONICET/ IIGG, Universidad de Buenos Aires, Argentina. Dra. Irene Molina, Uppsala Universitet, Suecia.

Dr. Gonzalo Lautaro Ojeda Ledesma, Universidad de Valparaíso, Chile.

Dra. Suzana Pasternak, Universidade de São Paulo, Brasil.

Dr. Javier Ruiz Sánchez, Universidad Politécnica de Madrid, España.

Dra. Elke Schlack Fuhrmann, Pontificia Universidad Católica de Chile, Chile.

Dr. Carlos Alberto Torres Tovar, Universidad Nacional de Colombia, Colombia.

Sitio web: http://www.revistainvi.uchile.cl/

Correo electrónico: revistainvi@uchilefau.cl Licencia de este artículo: Creative Commons Atribución-Compartirlgual 4.0 Internacional (CC BY-SA 4.0) 